\title{
NUEVOS DATOS SOBRE LA VIDA DEL AUTOR DE COMEDIAS BARTOLOMÉ DE MENDOZA*
}

\author{
IÑAKI PÉREZ-IBÁÑEZ \\ University of Rhode Island \\ ignacioperez@uri.edu
}

$P$ ocas son las noticias que tenemos sobre la vida del autor de comedias Bartolomé de Mendoza ${ }^{1}$. Las referencias documentales que tenemos sobre él son escasas y se concentran en el periodo que va de 1579 a 1589 . En el Diccionario biográfico de actores del teatro clásico español (DICAT) se recogen las noticias que se conocían de este autor en 2008, año de su publicación, y en las que baso el sucinto resumen que sigue a continuación.

En 1579 nuestro autor tuvo dificultades económicas que le obligaron a empeñar ropas para la representación durante su estancia en Málaga. En este momento se refieren a él como «vecino de Sevilla». Nada sabremos de su vida durante los próximos tres años. En el verano de 1582 reaparece en Tudela, donde se le pagaron 40 ducados por tres representaciones que realizó para las fiestas de Santiago, santa Ana y san Pedro. La orden de pago extendida a su favor está fechada el primero de agosto y el recibo de cobro el dos del mismo mes.

Las siguientes referencias a este autor recogidas en el DICAT se refieren a los años 1588 y 1589 . Se trata de dos contratos entre Bartolomé de Mendoza y la ciudad de Alcaraz (Albacete) para que este representase durante las celebraciones

* El presente trabajo ha sido posible gracias al apoyo del Dr. Peter Snyder, vicepresidente de Investigación y Desarrollo Económico, y del Dr. Anthony Rolle, decano de la Facultad de Educación y Estudios Profesionales, ambos de la Universidad de Rhode Island (Kingston, RI, EE.UU.). Su generosa financiación me permitió completar una estancia como investigador invitado en la Universidad de Navarra, el verano de 2019, durante la cual se gestó este proyecto.

1 En diferentes fuentes aparece citado como Bartolomé Mendoza, Bartolomé de Mendoza o Bartolomé de Mendoza y Castillo. Por nuestra parte, nos referiremos a este autor como Bartolomé de Mendoza, ya que así es como se recoge su nombre en el documento que descubrimos.

Edad de Oro, XXXIX (2020), pp. 101-116, ISSN: 0212-0429 - ISSNe: 2605-3314

DOI: https://doi.org/10.15366/edadoro2020.39.004 
del Corpus. En el primero de los contratos ${ }^{2}$, se refieren a él como «vecino de Jaén $»^{3}$ y se le contrató para representar un total de dos autos y dos entremeses por lo que recibió 40 ducados. Debieron de quedar muy satisfechos con su trabajo, ya que al año siguiente se le encargó la representación de dos comedias a lo divino y entremeses con acompañamiento musical por los que se le pagaron 70 ducados.

A estos datos debemos añadir los que se recogen en el documento que Julio I. González Montañés desenterró en 2014: un contrato entre Bartolomé de Mendoza y Antonio Pita Varela, vecino de Betanzos y mayordomo de la cofradía de san Roque. Está firmado el 24 de julio de 1583 en la ciudad de Santiago de Compostela ${ }^{4}$. En él, se comprometía a poner en escena dos comedias durante las fiestas en honor a san Roque: una comedia a lo divino que debía representarse el 21 de agosto y una a lo humano que se llevaría a las tablas al día siguiente. Ambas representaciones incluirían entremeses y máscaras al fin de cada obra y acompañamiento musical de «vihuela y voces». En pago por su trabajo, el autor iba a recibir 20 ducados.

Es bastante probable que, en su camino de Tudela hasta Betanzos, Bartolomé de Mendoza hubiese seguido el circuito norteño ${ }^{5}$, cuyo eje principal se hallaba en la vía que unía Valladolid y Zaragoza, pasando por Palencia, Burgos, Santo Domingo de la Calzada, Nájera, Logroño, Calahorra y Tudela ${ }^{6}$. Hacia occidente esta ruta tuvo extensiones hasta Salamanca, desde donde Mendoza pasaría a Santiago de Compostela ${ }^{7}$.

2 Aunque no lo menciona el DICAT, se recoge una transcripción de este contrato en Pérez Pastor (1914: 368, noticia 34).

3 Esto le llevó a Díaz de Escovar (1920: 119) a pensar que era natural de Jaén, «pues, aunque las escrituras solo le llaman vecino, harto sabido es que por lo regular se confundían ambas expresiones» (la cursiva aparece en el original).

4 Dicho contrato se conserva en el archivo de la catedral de Santiago, signatura P 087, ff. 84r-85r (antigua signatura 673c). González Montañés (2014) lo ha digitalizado y se puede consultar en la base de datos Teatro en Galicia. Noticias de representaciones hasta $1750<\mathrm{http}: / /$ representaciones.teatroengalicia.es>.

5 Para la descripción del circuito norteño, véanse Miguel Gallo (1996: 260, nota 3) y Domínguez Matito (2006: 92-93).

6 Un caso prototípico de un autor que completó el circuito norteño es el de Juan de Acacio (véase su entrada en el DICAT). De él sabemos que se encontraba en Madrid en agosto de 1623. Para mayo de 1624 ya había pasado a Zaragoza, desde donde se dirigió a Tudela. En esta localidad navarra se encontraba el 12 de agosto de ese mismo año. Existe evidencia documental de que un mes y medio después (el 27 de septiembre) se encontraba en Pamplona. Exactamente un año después, el 27 de septiembre de 1625, se halla pleiteando en Logroño, desde donde se dirigió a la ciudad de Burgos. Allí el 25 de noviembre contrata los servicios del carretero Luis Girón para que lleve sus bagajes a Palencia. Poco después del inicio del nuevo año ya está en Valladolid (19 de enero de 1626).

7 González Montañés afirma que lo más común era que las compañías teatrales llegasen a Galicia desde «Ourense, pasaran a Santiago y A Coruña o Betanzos y saliesen por Lugo (o a la inversa). 
A este puñado de datos conocidos hasta el momento debemos añadir los que se recogen en el documento que presento en este trabajo: un acta procesal procedente de los tribunales reales de Navarra, fechada el 5 de mayo de 1582. Se trata de un pleito que interpuso Mendoza contra Juan de Ibáñez Navarro, en la ciudad de Pamplona ${ }^{8}$. Se custodia en el Archivo General de Navarra bajo la signatura 212.316. En la carpeta de guarda se lee: «[Cruz] Proceso de Bartolomé Mendoza contra Juan de Ibáñez sobre cantidades. Hojas 11. Año 1582. Escribano Juan de Alaiz». En la parte superior derecha de la página leemos «n. ${ }^{\circ} 21 »$. Otra mano ha escrito los números 486 con lo que parece ser una pintura de cera de parafina (crayón o pintura plastidecor) de color rojo y la signatura (212.316) con otra de color verde oscuro. El auto no está foliado y se recogen un total de 13 folios $^{9}$. Las hojas 4r-v, 5r-v, 7v, 10r-v, 11r, 12r-v y 13r-v se hallan en blanco.

En este proceso se habla de Mendoza como residente en Pamplona ${ }^{10}$, lo que nos puede hacer pensar que llevaba algún tiempo en dicha ciudad. El interés del documento que presentamos a continuación no reside tanto en el lugar en el que gracias a él podemos localizar a nuestro autor (no debería sorprendernos encontrarlo en Pamplona a finales de abril, principios de mayo de 1582 si ya existían pruebas que lo ponían en Tudela el 1 de agosto de ese mismo año), sino en los motivos del pleito contra Juan de Ibáñez Navarro y en la cantidad de información sobre él y su compañía que podemos inferir.

La mayor parte venían contratadas por el Cabildo de Santiago, que pagaba muy bien, pero solía exigir que los contratados no actuasen en Galicia antes de haberlo hecho en Compostela, pudiendo luego actuar en otras villas, generalmente con tarifas considerablemente más bajas» (2009). Esta afirmación casa perfectamente con la información recogida en el contrato para representar en Betanzos que Mendoza firmó en Santiago de Compostela al que anteriormente nos hemos referido.

8 Al final de este estudio, se recoge una transcripción de la denuncia que Bartolomé de Mendoza presentó y que en el acta procesal se recoge en los ff. 6r-7r. Para las citas que se incluyen en el cuerpo del estudio, sigo los mismos criterios de transcripción que he seguido al transcribir la denuncia: he solucionado las abreviaturas, eliminado el uso de las consonantes dobles que me parecen innecesarias y modernizado la ortografía. También he añadido la puntuación indispensable para la correcta comprensión de los textos.

9 Aunque el documento no se encuentre foliado, nos referiremos a las páginas en el orden tal y como nos lo encontramos cuando lo consultamos. Para facilitar la localización del texto, indicaremos cuál es el testigo a cuya declaración nos referimos.

10 En la declaración de Gabriel de la Torre se lee: «El dicho Gabriel de la Torre, residente en esta ciudad, testigo presentado por parte de Bartolomé de Mendoza, autor de comedias, así bien residente en la dicha ciudad» (f. 8r). 


\section{El PAgo de LA REPRESENTACión}

El motivo del pleito no deja de ser curioso: Bartolomé de Mendoza había concertado con Juan de Ibáñez Navarro, alcaide de las cárceles reales, una representación frente a los presos y por la que, una vez realizada, exigía el pago. En el acta procesal del pleito se recoge la declaración de seis testigos. Por la defensa testificaron Rodrigo de la Cruz — comediante-, Miguel Martínez de Villaba ${ }^{11}$ y Diego Vázquez. A favor del demandante lo hicieron Gabriel de la Torre, Juan de Colón y Pablo de Espinosa (todos ellos actores). En el proceso aparecen las firmas de todos los testigos.

Según lo que se recoge en dichas declaraciones, la representación tuvo lugar el primero de mayo de 1582, martes por la noche. El motivo de las desavenencias se encuentra en que mientras Mendoza tenía claro que su trabajo debía ser pagado, el alcaide de la cárcel entendió que la representación se iba a hacer gratuitamente, por amistad al actor Rodrigo de la Cruz, para su regocijo y el de los demás reclusos ${ }^{12}$. Este se encontraba preso por motivos que se nos escapan (no se precisan en el auto) y recibía visitas de sus compañeros habitualmente con los que tañía y cantaba (Declaración de Diego Vázquez, f. 3v). Nuestro autor solicitaba el pago de tres ducados, cantidad que consideraba baja ya que representó «la mejor comedia que trae que, a justa y común estimación, valía seis ducados» (escrito de Bartolomé de Mendoza, f. 6r) y afirma que cada día que representaba con su gente ganaba «más de diez ducados» (escrito de Bartolomé de Mendoza, f. 7r). No exageraba: ya hemos dicho que el primero de agosto de ese mismo año recibió 40 ducados en pago por haber hecho en Tudela tres representaciones de autos y comedias. Por su parte el alcaide de la cárcel afirmaba que Mendoza había representado por voluntad propia y que en ningún caso se había concertado el pago por la representación. Consideraba la cena que les había servido como suficiente pago a sus servicios ${ }^{13}$.

Parece ser que actuar en la cárcel fue idea de Juan de Ibáñez. Cuentan los testigos que durante una de las visitas que Mendoza y algunos otros actores hicieron

11 Aunque en el DICAT se recogen noticias sobre un comediante llamado «Miguel Martínez» fechadas en 1594 y 1603, dudo que se trate de la misma persona. El testigo tenía en este momento 45 años y en su declaración habla de Mendoza y sus compañeros sin incluirse en el grupo, lo que me lleva a pensar que no formaba parte de la compañía.

12 En su declaración Miguel Martínez de Villaba afirma que «ha visto entrar en la dicha cárcel al dicho Mendoza y sus compañeros a visitar a Rodrigo de la Cruz, preso con el cual solían estar en conversación. Y este testigo algunas veces se halló presente con ellos y, tratando de comedias, les oyó decir que si hubiese lugar en la dicha cárcel harían una comedia por amor del dicho Rodrigo de la Cruz y por lo regocijar y por ser amigo» (f. $2 \mathrm{v}$ ).

13 «La colación» que Mendoza y los demás miembros de su compañía recibieron tras la representación aparece mencionada en la declaración de Rodrigo de la Cruz (f. 2v) y de Miguel Martínez de Villaba (f. 3r). 
a Rodrigo de la Cruz en la cárcel, el alcaide se les acercó y sugirió que hiciesen una representación para entretener a su compañero y los demás presos ${ }^{14}$. Mientras que los testigos que declararon a su favor afirmaban que en ningún momento se habló en su presencia del pago de «intereses» por el trabajo de Mendoza y su compañía ${ }^{15}$, nuestro autor y sus compañeros testificaron que en múltiples ocasiones intentaron acordar con él una cantidad, pero que este se negó a concertar el precio. Cuando el alcaide de las cárceles reales se acercó por primera vez a Mendoza para pedirle que hiciese una representación, este mostró su preocupación ya que en la cárcel no había suficientes presos como para que le resultase rentable ${ }^{16}$. La capacidad de las cárceles reales de Pamplona era muy pequeña ${ }^{17}$, por lo que las reticencias de nuestro autor tenían plena validez. Este intentó en tres ocasiones convenir un precio e incluso sus actores afirmaron que se negarían a representar si no había un acuerdo de por medio. En su declaración, Gabriel de la Torre afirmaba que «le dijeron [a Mendoza] que no irían a representarla sin que primero concertase el precio que les había de dar» (f. 8v). Por su parte, Mendoza declaró que había enviado recado a Juan de Ibáñez para que o bien concertase el precio, o bien les devolviese «las ropas de farsa» (escrito de Bartolomé de Mendoza, f. 6v). Desafortunadamente para él, su mensajero no pudo hablar con el alcaide

14 «El martes último pasado, que se contaba presente del primero del presente mes de mayo, el dicho Mendoza: fue a la dicha cárcel a visitar a este testigo y estando con él hablando, el dicho alcaide dijo al dicho Mendoza "haga vuestra merced aquí alguna cosa para regocijar a esos presos". Y el dicho Mendoza dijo que él haría una comedia y que cuándo era servido de que la hiciera. El dicho alcaide le dijo que cuando él quisiese la podría hacer, y con esto se despedieron [sic]» (declaración de Rodrigo de la Cruz, f. 2r). De esta declaración se infiere que dicha conversación tuvo lugar el mismo 1 de mayo, día de la representación. Nos parece más creíble que esto fuera antes. Juan de Colón en su declaración del 4 de mayo (f. 9r) habla de «seis u ocho días», mientras que Miguel Martínez de Villaba fija el plazo en «ocho días» (f. 2v), lo que indicaría que este acercamiento tuvo lugar entre el 27 y 29 de abril.

15 Así, por ejemplo, en la declaración de Rodrigo de la Cruz leemos: «El dicho Mendoza representó en la dicha cárcel una comedia, pero nunca trataron entre ellos de interese [sic] ninguno, ni el dicho Mendoza se le pidió. Y este testigo tuvo por cierto que el dicho Mendoza no pidiria [sic] interese ninguno por ello hasta que después, el dicho Mendoza, dijo a este testigo si sabía si la comedia le habían de pagar» (f. 2v).

16 Según declaró Gabriel de la Torre, Mendoza dijo que «había pocos presos en ella [la cárcel] para poder ser pagado y que si hubiese tantos presos como en otras cárceles suele haber de caballeros y mercaderes ricos, la harían» (declaración de Gabriel de la Torre, f. 8r).

17 «Lo que nos parece más evidenciable es que el número de presos que en realidad podían albergar esas instituciones [cárceles reales y la cárcel para mujeres (casa-galera)] nunca hubo de ser muy grande, aunque eso también fuera muy relativo. Puede que en determinados períodos se generaran verdaderos problemas de superpoblación carcelaria [...], pero todo indica que su carácter eminentemente procesal y otros criterios más propiamente de economía presupuestaria incidieron en que a lo largo de todo el Antiguo Régimen sucediera más bien lo contrario y que habitualmente no fuera muy grande la cantidad de presos en las cárceles pamplonesas» (Oliver Olmo, 2000: 74). 
por no encontrarse este en casa en ese momento, así que, fiado de la palabra dada, persuadió a su compañía para que accediesen a actuar, convencidos de que se les pagaría y contentaría muy bien. Cuando al día siguiente fue a reclamar el pago, Juan de Ibáñez se llamó a andanas, con la esperanza de que al estar Mendoza y su compañía a punto de partir pudiese evitar el pago. Este, prefirió aplazar la partida (a pesar del perjuicio que esto le suponía, pues tenía que pagar por las mulas que tenía alquiladas para el transporte de su compañía a su próximo destino ${ }^{18}$ ) y reclamar el pago de su trabajo. Finalmente, el juicio se oyó el 4 de mayo y el alcaide Villagómez, que ejerció como juez, falló a favor del demandante, exigiendo a Juan de Ibáñez que pagase la cantidad de 26 reales, lo cual hizo ese mismo día ${ }^{19}$.

\section{LA REPRESENTACIÓN}

Tal y como hemos mencionado anteriormente, la representación se llevó a cabo el martes, primero de mayo de 1582 por la noche. No sabemos cuál fue la obra que se representó, aunque Mendoza afirma que era de las mejores en su repertorio y que el trabajo recibió el aplauso del público. El lugar no deja de ser llamativo, dadas las condiciones de los centros penitenciarios en la época, entre ellas, las cárceles reales de Pamplona. Construidas en 1541, estas se encontraban situadas entre las actuales calles Eslava, la calle Nueva y la plaza de San Francisco ${ }^{20}$. Son numerosos los testimonios, tanto históricos como literarios, que nos hablan de las duras condiciones en las que se encontraban los presos. Recordemos que los propios reclusos eran los encargados de pagar por su propia manutención, en un sistema que recuerda a un régimen de pensión, lo que para quienes carecían de recursos generaba una situación dantesca ${ }^{21}$. La descripción del sistema carcelario

18 Leemos en la declaración de Juan de Colón que «el dicho Mendoza está ya de partida y se detiene solo por este negocio, haciendo costas con cabalgaduras alquiladas» (f. 9r). El propio Mendoza también hace referencia a estos gastos (véase la transcripción de su escrito al final de este trabajo). Era habitual que los comediantes no dispusieran de caballerías propias ni de carros y que los diferentes pueblos y ciudades con los que firmaban contratos para representar ayudasen a pagar estos gastos con lo que se conocía como la «ayuda de costa».

19 Se recoge la sentencia y un recibo por el pago de 26 reales en el f. 11v del auto. La sentencia, dictada por el alcalde Villagómez dice así: «Vistos estos autos se condena el alcaide de la cárcel a que pague luego y que este auto se le notificare a Bartolomé de Mendoza, comediante, veinte y seis reales por su trabajo de la comedia que hizo en la cárcel, con apercibimiento que, no los pagando luego, estará a su costa». Si consideramos que un ducado equivalía a 11 reales castellanos, debemos afirmar que, aunque Mendoza no recibió la compensación que solicitaba, sí que estuvo bastante cerca de conseguirlo. Para la estructura monetaria que regía en el reino de Navarra en el siglo XVI, véase Pascual Bonis (1990: 14).

20 Así lo confirman Virto Ibáñez (1993: 633) y Francés Lecumberri (2015: 458).

21 «Puede decirse que el carácter venal de los cargos, el sistema de autofinanciación de los presos y el escaso control ejercido por las autoridades superiores provocan un estado de injusticia y 
pamplonés y condiciones en las que vivían los presos de la capital navarra que hace Berraondo Piudo resulta ilustrativa:

[La cárcel] en aquella época era una institución con una finalidad no punitiva, sino un lugar en el que los criminales esperaban su sentencia mientras duraba el proceso contra ellos. Podemos decir que la cárcel formaba parte de la acción judicial y, de hecho, las Cárceles reales de Pamplona se encontraban ubicadas al lado del edificio del Consejo Real. Las condiciones de vida en las cárceles no eran idóneas. Los presos $[\ldots]$ pasaban frío, hambre, interrogatorios, torturas y diversos abusos por parte de los carceleros, y frecuentemente solían quejarse de las duras condiciones en las que vivían. El paso por las Cárceles reales suponía un grave problema tanto para los presos como para sus familias, pues los presos debían sustentarse a sí mismos. En cierto modo, podemos considerar el ingresar en la cárcel como una pena (2010: 229) $)^{22}$.

Por todo ello resultaría extremadamente chocante que Juan de Ibáñez propusiese una representación para el regocijo de los presos, tal y como él y sus testigos afirmaron ante el tribunal. Más bien fue un festejo privado que el alcaide de la cárcel quiso hacer para entretener a sus amistades y conocidos. Así cuando Mendoza expresó su preocupación por el escaso público (dado los pocos reclusos que habían en la cárcel en ese momento) y, consecuentemente, por lo mal que se le pagaría por su trabajo, el alcaide afirmó que él llamaría a gran cantidad de escribanos, procuradores, pleiteantes y sus mujeres. Finalmente, el público no se compuso principalmente por presos, sino por gente de calidad, ya que según la declaración de Mendoza «el dicho alcaide convidó muchas damas principales y otras gentes para ver la dicha representación» (escrito de Mendoza, f. 6r).

Dada la premura con la que se organizó (el mismo día de la representación por la mañana la compañía todavía no había aceptado representar), debemos pensar en una puesta en escena muy simple. El bajo estipendio que pedía Mendoza (tres ducados frente a los hasta 10 que cobraba normalmente por un día de trabajo) no hacen sino apoyar esta hipótesis. Esta se debió de hacer en el mismo patio de la

corrupción por parte de los responsables de la cárcel, mientras que los presos son víctimas de una situación penosa y ciertamente desamparada unas veces, y otras, hacen alarde de una permisividad que hoy puede parecer increíble. En cualquier caso, el alcaide es como un reyezuelo barrigón y tirano, y los porteros y aún [sic] los asistentes de los "pobres presos" aprovechan toda oportunidad en beneficio propio, porque no hay nada que impida los posibles fraudes» (Vázquez González, 1984: 32).

22 Virto Ibáñez habla de las condiciones sanitarias del presidio en 1771, con una enfermería abarrotada por numerosos reclusos enfermos, debido a la frialdad del edificio, la escasez de carbón, la suciedad, la humedad y, sobre todo, a la falta de alimentos. Los presos más pudientes pagaban 27 maravedís diarios al alcaide para quedarse en un cuarto separado (llamado el cuarto de las camas) donde las condiciones eran significativamente mejores (1993: 633-634). 
cárcel sobre un tablado, si es que lo hubo, montado sobre caballetes de soporte o barriles. Los espectadores verían la representación o bien de pie o en bancos y sillas llevados al patio para la ocasión. Al parecer, las ropas para la representación se llevaron a la cárcel, cuando menos, el día anterior ${ }^{23}$.

\section{La Compañía de Mendoza}

El listado de testigos nos permite elaborar una lista parcial del elenco de actores que formaban la compañía de Mendoza en 1582. La primera declaración que se recoge en el auto es la de Rodrigo de la Cruz, quien se encontraba preso por motivos que desconocemos. Este documento nos permite añadir algo de información a lo poco que hasta el momento conocíamos de este actor. Tan solo se sabía que estuvo casado con Juana de Espinosa y que entre el 30 de octubre de 1595 y carnaval de 1597 formó parte de la compañía de Nicolás de los Ríos ${ }^{24}$. Cuando prestó declaración en contra de nuestro autor de comedias, tenía «18 años, poco más o menos». Según se deduce de su escrito, nuestro autor negó que De la Cruz fuese parte de su compañía (o que incluso lo conocía) ${ }^{25}$, y este testificó que conocía «a los dichos alcaide y Mendoza de vista tan solamente» (declaración de Rodrigo de la Cruz, f. 2r). Si nos fijamos en los testimonios de todos los demás testigos, esta afirmación resulta difícil de sostener. Al finalizar el pleito, Mendoza siguió su camino mientras que, al parecer, Rodrigo de la Cruz quedó preso. Probablemente, por este motivo testificó a favor del alcaide, si bien esto es mera conjetura.

En el f. 8r-v se recoge la declaración del actor Gabriel de la Torre. Son numerosas las noticias que tenemos sobre este autor. La primera mención documental sobre él era de 1589, momento en el que firmó con su mujer Melchora de Rojas una obligación de pagar 38 ducados a Diego Páez por unos vestidos para representar $(D I C A T)$. Según su declaración en este auto en 1582, tenía 20 años poco más o menos. Podemos deducir que, de una forma u otra, llevaba ya varios años en el mundo de la farándula, ya que afirmó conocer a Mendoza desde hacía seis años, si bien formaba parte de su compañía desde hacía tan solo tres

23 Recordemos que, tal y como se ha mencionado anteriormente, el primero de mayo, día de la representación, Mendoza mandó buscar a Juan de Ibáñez o para concertar el pago de su trabajo o para que les devolviese su vestuario («ropa de farsa»).

24 Consta un documento, fechado en Toledo el 30 de octubre de 1595, por el que Rodrigo de la Cruz, representante y vecino de Sevilla, se comprometía en su nombre y en el de su mujer, Juana de Espinosa, a formar parte desde ese día hasta el de carnaval de 1597 de la compañía de Nicolás de los Ríos, autor de comedias, vecino de Toledo, por lo que el matrimonio recibiría 220 ducados, cinco reales cada día para comer y cama, y tendría los viajes pagados (DICAT).

25 En su escrito de denuncia Mendoza pide que se pregunte a los testigos «Si saben que el dicho Mendoza no conoce al preso que dicen que está en la dicha cárcel que se llama Rodrigo; ni el dicho Mendoza ni ninguno de sus compañeros no le conocen ni le han visto en toda su vida» (f. 6v). 
meses. Este documento nos permite adelantar con total seguridad el inicio de su carrera de actor por lo menos hasta 1582: pasó al menos 42 años en las tablas ${ }^{26}$.

Gracias a esta acta procesal podemos añadir dos nombres al listado de actores de esta primera etapa del teatro comercial y que, en lo que se nos alcanza, eran comediantes desconocidos hasta el momento. El primero de ellos es Juan de Colón «natural de la ciudad de Sevilla al presente residente en la dicha ciudad de Pamplona», quien tenía «dieciocho años poco más o menos» (declaración de Juan de Colón, ff. 8v y 9r) y formaba parte de la compañía de Mendoza desde los trece ${ }^{27}$. No se recogen datos sobre cuál era su función en la compañía (tipo de papeles que interpretaba, si era músico, danzante, etc.).

El segundo comediante del que hasta ahora no se tenía noticia es Pablo de Espinosa. Los datos que se nos proporcionan de él son todavía más escasos. En su declaración afirmó que tenía «veinte y dos años poco más o menos, y que de cuatro o cinco meses a esta parte conoce al dicho Mendoza porque en todo el dicho tiempo ha andado y anda en su compañía». Nada se dice de su lugar de origen o de cuál era su función en la compañía.

Resulta llamativo lo jóvenes que eran todos los actores que declararon. Sus edades estaban comprendidas entre los dieciocho (Rodrigo de la Cruz y Juan de Colón) y los veintidós años (Pablo de Espinosa). Tal y como se ha mencionado anteriormente, Gabriel de la Torre tenía entonces veinte años.

Quiero acabar este artículo citando a Pascual Bonis, quien constató «la gran cantidad de información contenida en [...] los procesos civiles y religiosos» (1996: 301) para el estudio del teatro áureo y «la necesidad de seguir explorando estas fuentes» (1996: 308). Todavía queda mucho por hacer en este respecto y los archivos judiciales son un área que puede seguir dando numerosos frutos.

\section{APÉNDICE: TRANSCRIPCIÓN DE LA DENUNCIA \\ de BARTolomé de Mendoza (FF. 6R-7R)}

[F. 6r] [Cruz] Sacra Majestad

Bartolomé de Mendoza, autor de comedias, digo que habiendo tratado con el alcaide de la cárcel de vuesa majestad que le representase una comedia en la dicha cárcel y que él me lo pagaría muy bien, debajo de lo cual yo, con todos mis compañeros, le representamos la dicha comedia. Y agora el susodicho dice que no trató conmigo cosa alguna para lo cual me conviene averiguar lo contrario. Pido y

\footnotetext{
26 Se conserva su testamento fechado en julio de 1624 en Madrid, donde «tenía compañía de los corrales de las comedias de esta Corte» (DICAT).

27 Afirmó «que de cinco años a esta parte conoce al dicho Mendoza y que en todo el dicho tiempo anda en su compañía» (declaración de Juan de Colón, f. 9r).
} 
suplico a vuesa majestad que los testigos que presentare se examinen por el señor del tal [ilegible] Laínez ${ }^{28}$.

[Item] Si saben que, el dicho alcaide tratando con el dicho Mendoza de la dicha representación, dijo el dicho Mendoza que en la cárcel de esta ciudad había pocos presos y que le sería por esta razón mal pagada; a lo que el dicho alcaide respondió que él juntaría gran suma de escribanos y procuradores y pleiteantes con todas sus mujeres, y que de todos cobraría lo que pudiese. Y que, no obstante esto, él de su parte daría y pagaría al dicho Mendoza muy bien su trabajo. Por razón de este concierto el dicho Mendoza representó la mejor comedia que trae que, a justa y común estimación, valía seis ducados y el dicho alcaide convidó munchas $[s i c]$ damas principales y otras gentes para ver la dicha representación. Digan lo que saben.

[F. 6v] [Item] Si saben que el dicho alcaide envió una y dos y tres veces con mucha importunación a llamar al dicho Mendoza para que se concertase con él por qué precio haría la dicha comedia. Y persuadido del dicho alcaide, el dicho Mendoza fue a concertarse y tratando del concierto, el dicho alcaide dijo que no había para que concertallo, que debajo de su palabra fuesen a hacer la dicha comedia, que él los contentaría muy bien. Y debajo de esta palabra el dicho Mendoza fue a la cárcel y representó la comedia. Digan que lo saben. Etcétera.

[Item] Si saben que los compañeros del dicho Mendoza, visto que no había concertado ni aclarado con el dicho alcaide lo que le habían de dar por la dicha comedia, no querían ir a representar. Y el dicho Mendoza envió a decir al dicho alcaide que le enviase a decir lo que se le había de dar por la dicha comedia y, que si no, que le volviesen su ropa de farsa a su posada. Y no se halló el dicho alcaide en aquella sazón en casa.

[Item] Si saben que lo que Mendoza paga a sus compañeros las representaciones que hacen y les da de comer y posadas y cabalgaduras a su costa; y que si el dicho Mendoza no [tachado] representa, les paga luego su trabajo. Y que ellos no pueden tratar ni concertar comedia ninguna, ni convidar con ella a nadie, porque es hacienda suya propiamente. Digan que lo saben. Etcétera.

[Item] Si saben que el dicho Mendoza no conoce al preso que dicen que está en la dicha cárcel que se llama Rodrigo; ni el dicho Mendoza ni ninguno de sus compañeros no le conocen ni le han visto en toda su vida. Digan lo que saben. Etcétera.

[F. 7r] Otrosí pido y suplico a vuestra majestad, atento que yo estoy de camino y pago las cabalgaduras de vacío, mande al dicho alcaide nos pague luego la dicha

28 Laínez: lectura dudosa. 
representación con apercibimiento que cobrare del susodicho todos estos daños, intereses y menoscabos que se me siguieren y recibieren ${ }^{29}$, con más de diez ducados que gano con mi gente todos los días que represento. Y pido se le notifique que para lo cual pido, etcétera ${ }^{30}$.

[Firma] Bartolomé de Mendoza

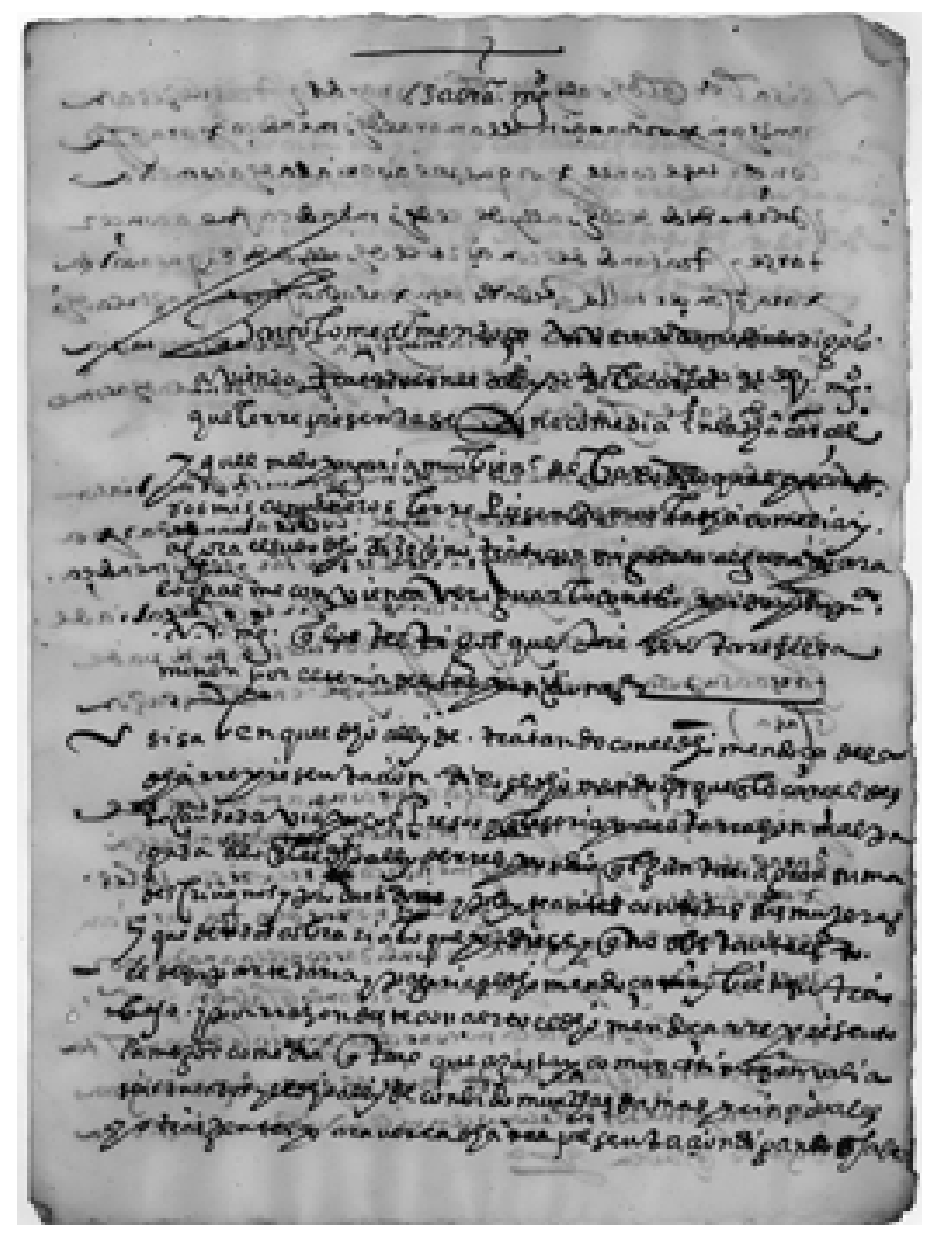

[Imagen 1]. Escrito de Bartolomé de Mendoza, AGN, Corte Mayor, proceso 212.316, f. 6r.

29 recibieren: lectura dudosa

30 Aquí «etcétera» equivaldría a «justicia y costas», fórmula habitual de terminar este tipo de escritos. 


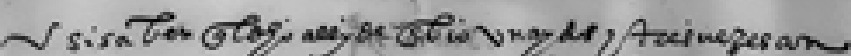

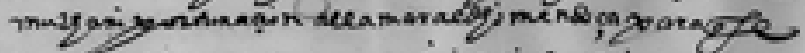

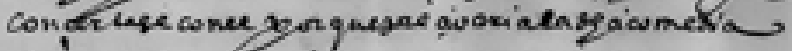

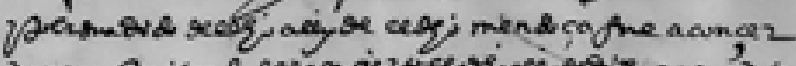

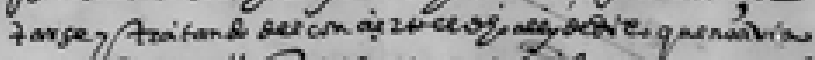

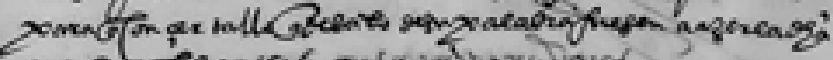

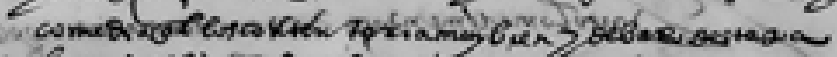



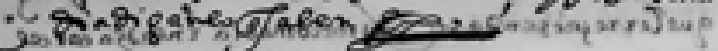

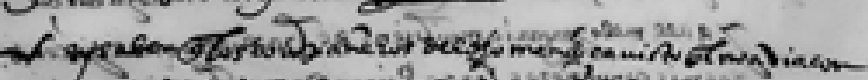

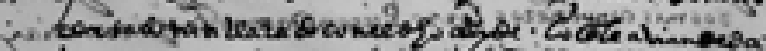

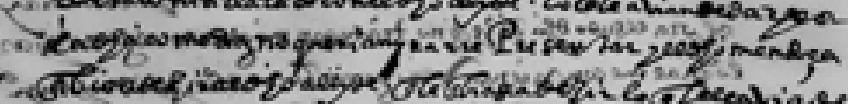



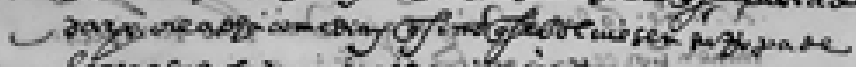

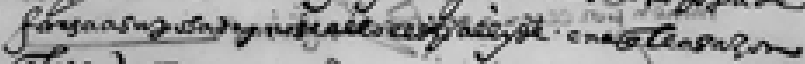



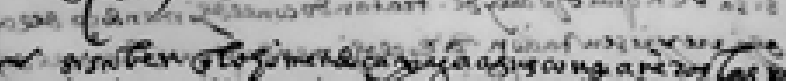
or

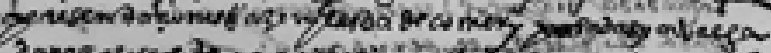



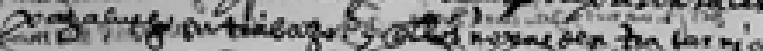

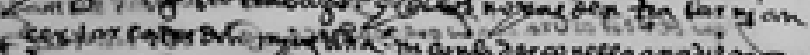

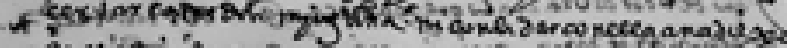

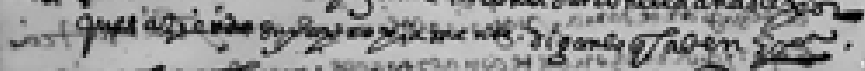

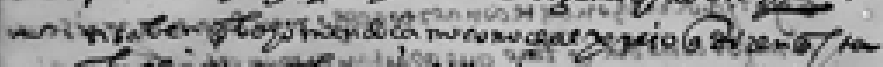

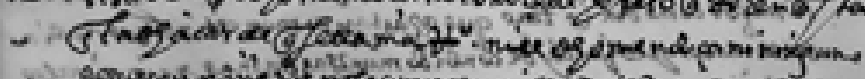

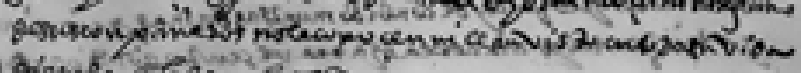

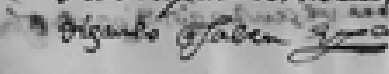

[Imagen 2]. Escrito de Bartolomé de Mendoza, AGN, Corte Mayor, proceso 212.316, f. 6v. 


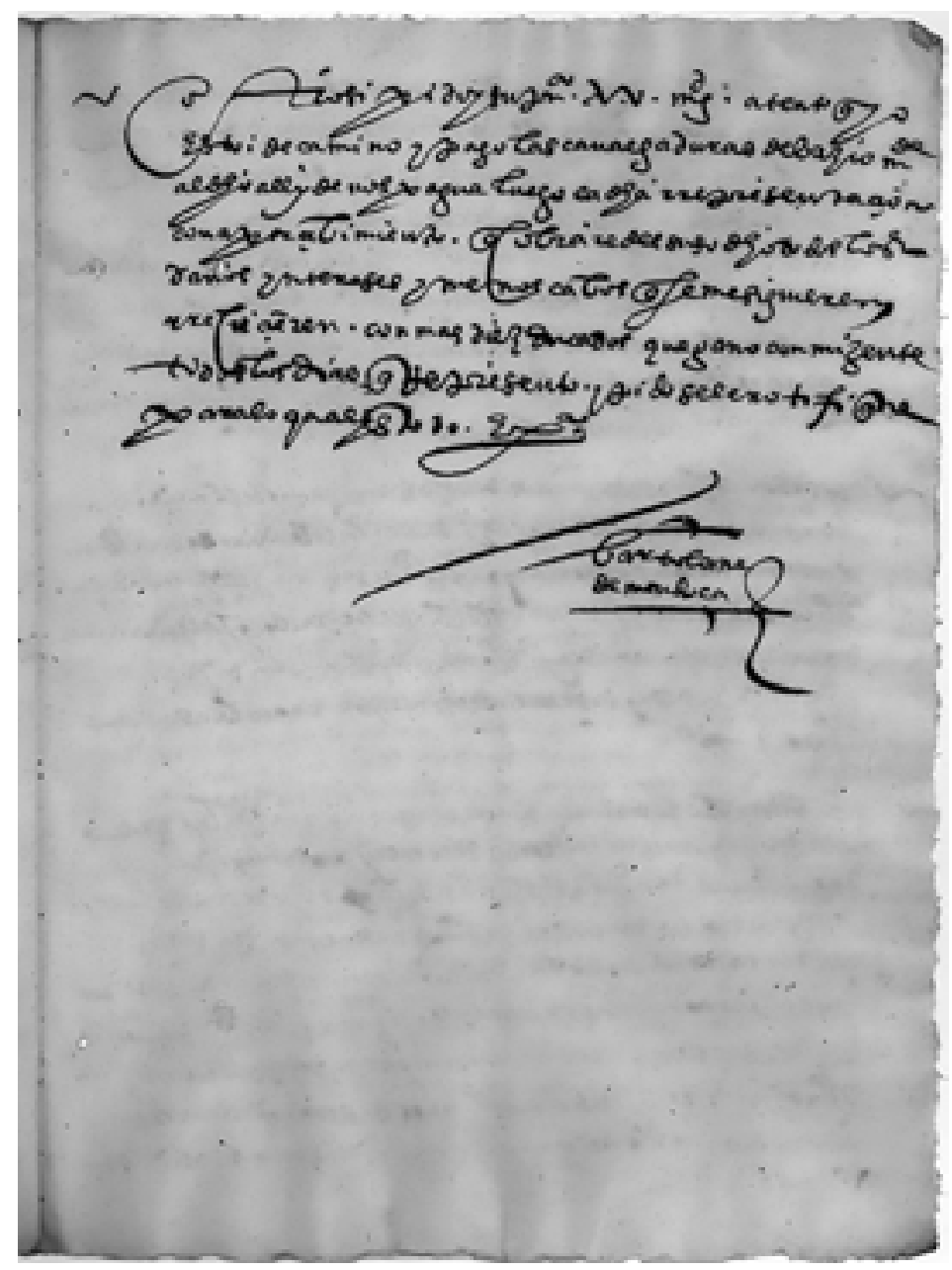

[Imagen 3]. Escrito de Bartolomé de Mendoza, AGN, Corte Mayor, proceso 212.316, f. 7r. 
BiBLIOGRAFÍA

Berraondo Piudo, Mikel (2010). «La violencia interpersonal en una ciudad fronteriza: el caso de Pamplona (1500-1700)». Manuscrits, 28, pp. 207-242.

De Miguel Gallo, Ignacio Javier (1996). «Balance de la actividad teatral en Burgos en el siglo XVII». En Ignacio Arellano Ayuso, Carmen Pinillos Salvador, Marc Vitse y Frédéric Serralta (coords.), Studia aurea: actas del III Congreso de la AISO (Toulouse, 1993). Pamplona / Toulouse: GRISO / LEMSO, vol. II, pp. 259-268.

Díaz de Escovar, Narciso (1920). «Otro cómico de Jaén. Bartolomé de Mendoza». Don Lope de Sosa, 88, pp. 119-120 <http://www.vbeda.com/Donlope/index0. php?anno=8> [Consulta: 01/08/2019].

Domínguez Matito, Francisco (2006). «Para la geografía teatral en el norte de la península». En Felipe B. Pedraza Jiménez, Rafael González Cañal y Elena E. Marcello (coords.), El corral de comedias, espacio escénico, espacio dramático. Actas de las XXVII Jornadas de teatro clásico de Almagro 6, 7, 8 de julio de 2004. Cuenca: Universidad de Castilla-La Mancha, pp. 87-120.

GonzÁlez Montañés, Julio I. (2009). Compañias profesionales en Galicia <http:// teatroengalicia.es/companias.htm> [Consulta: 01/08/2019].

GonzÁlez MontaÑÉs, Julio I. (2014). Teatro en Galicia. Noticias de representaciones hasta 1750 $<\mathrm{http}$ ://teatroengalicia.es/bases/representaciones/?-table=representaciones\&action $=$ browse $\&$-cursor $=0 \&$ Numero $==43>$ [Consulta: $01 / 08 / 2019]$.

Ferrer Valls, Teresa (dir.) (2008). Diccionario biográfico de actores del teatro clásico español (DICAT) [edición digital]. Kassel: Edition Reichenberger.

Francés Lecumberri, Paz (2015). «El encierro y el destino de las mujeres presas en Navarra». Iura Vasconiae, 12, pp. 441-498.

Oliver Olmo, Pedro (2000). La cárcel y el control del delito en Navarra entre el antiguo régimen y el estado liberal. Antonio Rivera Blanco (dir.) [tesis doctoral]. Bilbao: Universidad del País Vasco <https://dialnet.unirioja.es/descarga/tesis/41538.pdf> [Consulta: 01/08/2019].

Pascual Bonis, María Teresa (1990). Teatros y vida teatral en Tudela: 1563-1750. Estudio $y$ documentos. London: Tamesis Books / Gobierno de Navarra.

Pascual Bonis, María Teresa (1996). «El teatro como causa de procesos civiles y religiosos en la Navarra de los siglos XVI y XVII». En Ignacio Arellano Ayuso, Carmen Pinillos Salvador, Marc Vitse y Frédéric Serralta (coords.), Studia aurea: actas del III Congreso de la AISO (Toulouse, 1993). Pamplona / Toulouse: GRISO / LEMSO, vol. II, pp. 301-308.

Pascual Bonis, María Teresa (2002). Teatro, fiesta y sociedad en Pamplona de 1600 a 1746: estudio y documentos. José María Díez Borque (dir.) [tesis doctoral]. Madrid: Universidad Complutense de Madrid <https://dialnet.unirioja.es/servlet/ libro?codigo $=107684>$ [Consulta: 01/08/2019].

Pérez Pastor, Cristóbal (1914). Nuevos datos acerca del histrionismo español en los siglos XVI y XVII. Segunda Serie. Burdeos: Feret. 
VÁzQuEz GonZÁLEZ, Dolores (1984). «La cárcel y los presos en el Madrid Barroco». Villa de Madrid, 82, pp. 31-42.

VIRTo IbÁÑEZ, Juan Jesús (1993). «“La Galera” de Pamplona: cárcel de mujeres en el reino de Navarra». Príncipe de Viana, Anejo 15, pp. 631-639.

Recibido: 07/08/2019

Aceptado: 04/03/2020

Edad de Oro, XXXIX (2020), pp. 101-116, ISSN: 0212-0429 - ISSNe: 2605-3314 


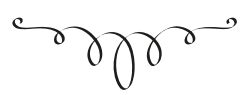

Nuevos datos sobre la vida del autor de comedias Bartolomé de Mendoza

RESUMEN: En el presente estudio damos a la luz un documento de 1582 que nos permite conocer nuevos datos sobre el autor de comedias Bartolomé de Mendoza. Se trata de un proceso que este interpuso contra Juan de Ibáñez, alcaide de las cárceles reales de Pamplona, por el pago de tres ducados por una representación que hizo en las mismas. Este documento nos proporciona interesantes datos sobre aspectos tales como la representación, el ámbito de representación, la compañía de Mendoza y la vida de los actores en el siglo XVI.

Palabras clave: Bartolomé de Mendoza, ámbitos de representación, cárceles reales, Pamplona.

\section{New insights about actor Bartolomé de Mendoza's life}

AвSTRACT: The present study aims to bring to light a document from 1582 that uncovers new information about actor (autor de comedias) Bartolomé de Mendoza. The document consists of a legal claim that the autor brought against Juan de Ibáñez, the ward of the Royal Prison of Pamplona, for three ducados in payment for a performance that took place in the prison. The document provides new details and insights into the nature of performances, types of performance venues, Mendoza's theater troupe and the life of actors in sixteenthcentury Spain.

Keywords: Bartolomé de Mendoza, Performance Venues, Royal Prison, Pamplona. 